\title{
USE OF ORNAMENTAL POTENTIAL OF INFLORESCENCES IN SELECTED SPECIES OF SEDGES (CAREX L. - CYPERACEAE) THROUGHOUT THE VEGETATION SEASON
}

\author{
Magdalena Janyszek, Dorota Wrońska-Pilarek, MieczysŁaw GrzelaK
}

\begin{abstract}
M. Janyszek, Department of Botany, Poznań University of Life Sciences, Wojska Polskego 71 C, 60-625 Poznań, Poland, e-mail: carexmag@au.poznan.pl

D. Wrońska-Pilarek, Department of Natural Forest Botany, Poznań University of Life Sciences, Wojska Polskiego 71 D, 60-625 Poznań, Poland, e-mail: pilarek.d@up.poznan.pl

M. Grzelak, Department of Grassland and Natural Landscape Sciences, Poznań University of Life Sciences, Dojazd 11,60-632 Poznań, Poland, e-mail: grzelak@up.poznan.pl
\end{abstract}

(Received: June 11, 2014. Accepted: November 4, 2014)

\begin{abstract}
AвSTRAct. Sedges are attractive ornamental plants, thanks to the specific structure of their inflorescences, perigynium morphology, an interesting habit and extended dates of individual phenological stages varying between species. Analyses were conducted on 15 sedge species differing in traits of their inflorescence shoots and varying in the shape and size of perigynia. Species characteristic of diverse habitats were selected so that they would meet the full spectrum of requirements of landscape architects. A nine-point scale was applied in this study, in which the decorative value of the investigated sedges was assessed. The greatest decorative value scores were recorded for Carex spicata, C. remota and C. pallescens (19 points each) and C. paniculata (18). In contrast, the lowest scores were found for C. ericetorum (12), C. digitata (13) and C. curta (14). Sedges planted in gardens are highly desirable elements of the landscape, particularly thanks to the phenotypic plasticity observed practically in all species throughout the entire vegetative season.
\end{abstract}

KeY WORDS: Carex, grass gardens, sedge inflorescences, compositions

\section{INTRODUCTION}

In recent years on the market of ornamental plants we have been observing an increasing interest in the category of plants referred to in trade as landscape grasses (FoERster 1982). This group, due to the similarity in the habit of their vegetative parts and the comparable habit of their inflorescences, combines representatives of three families - Poaceae, Cyperaceae and Juncaceae. Both grasses and sedges, as well as rushes are used in gardens as ornamental plants, not thanks to the value of flowers themselves, but rather the interesting appearance of their inflorescences, texture and hues of leaves, and the characteristic habit of plants, providing gardens with a unique atmosphere. For some time now representatives of the genus Carex have been gaining increasing popularity as commercially available landscape grasses. At present around a dozen sedge species are used as ornamental plants, both grown as cultivars and as wild forms, frequently collected directly from natural localities. However, despite the growing interest in this group of plants, their value in landscaping is still underestimated. Hopefully, this may change, since as a genus they have an interesting habit, differing greatly from species to species in terms of plant height, the shape and arrangement of tufts, arrangement of leaves (erect, creeping, etc.) and their colour. Another important and characteristic feature of sedges is their inflorescence morphology, varying greatly between species, constituting their distinct decorative value and being an essential component of plant compositions. Additional decorative advantages of sedges include the ornamental value of whole tufts, which may be appreciated throughout the entire vegetation season and occasionally even in winter, and the visual attractiveness of their perigynia, which in individual species may differ greatly in shape, size and colour. At present sedge representatives grown most commonly in gardens and frequently available 
in retail include C. ornithopoda $\mathrm{L}$. in cultivars, C. paniculata L., C. canescens L., C. remota L., C. caryophyllea Latour, C. flacca Schreb,. C. comans Bergger, C. buchananii Bergger and many other cultivars in numerous leaf colour varieties. Other examples of very attractive sedges are also $C$. aurea Nutt. and C. baccans Nees with highly decorative, colourful perigynia (URBAŃSKI 2001, Fech et al. 2007, Pudelska 2007, Rak 2009, Grabowska \& Kubala 2011).

The main aim of this study was to assess the suitability of fifteen selected species from the genus Carex for decorative purposes, as ornamental plants used in garden landscaping. This assessment concerned generative elements, particularly perigynia, which are of considerable decorative value. Observations were based, to a considerable extent, on the phenological aspects of sedges. Determination of the dates of onset and duration of successive phenological stages, even if only approximate, in the case of these species is crucial for the design of compositions and arrangements of individual taxa to achieve the decorative effect and to provide desirable variety (e.g. continuous flowering, fruiting or the length of perigynium presence on plants). It needs to be stressed here that literature sources presently available and connected with various aspects of phenology in representatives of the genus Carex are scarce (e.g. RatLIFF \& WesTfal 1992, Wagner \& Reichegger 1997, Stenström \& Wagner 2008, Hoffmann et al. 2010).

\section{MATERIAL AND METHODS}

Observations and analyses were conducted on representatives of 15 sedge species: C. bohemica Schreb., C. brizoides L., C. caespitosa L., C. curta Good., C. digitata L., C. ericetorum Poll., C. flava L., C. ovalis Good., C. pallescens L., C. paniculata L., C. pseudocyperus L., C. remota L., C. spicata Huds., C. sylvatica Huds. and C. vesicaria (O.F. Lang) Christ. The species were selected to vary to the greatest possible extent in terms of their morphology of generative elements, including inflorescence shoots at the flowering and fruiting phases and in terms of variation in perigynium shapes and sizes. Individual species are typical of different habitats and they were selected so that they would meet a full spectrum of requirements of landscape designers, both to supplement other compositions, as single species and as a composition comprising only representatives of the genus Carex. Analyses and observations were conducted in 2011-2012 . Specimens came from natural localities, from which they were collected at the beginning of the vegetation season of 2011 and they were planted in the garden at the same time. Individual phenological stages were recorded at the flowering phase at every five days and in the fruiting phase at every 10 days.

The decorative value was assessed based on observations of five tufts for each of the investigated species. These observations were carried out from the beginning of April, i.e. the time of development of the first flowers (C. digitata) up to the end of September, when the last plants started to lose perigynia (C. spicata, C. pseudocyperus). This assessment of a given species was based on observations of these characteristics, which had decorative value. In the case of sedges these were the date of development of the first flowers, the duration of flowering of individual tufts measured from the emergence of the first inflorescences at anthesis to the drying of the last inflorescences within tufts, the number of inflorescence shoots during the vegetation season, continuity of flowering expressed in terms of the sequence of emergence of inflorescence culms, coexistence of flowering and fruiting shoots, length of inflorescences, the date of appearance of the first mature perigynia, the duration of mature perigynia on the culm and the date of perigynium loss from mature inflorescences. Results were recorded in absolute values, which were later classified into groups, constituting the basis for the scoring system in the evaluation of decorative value for representatives of individual species. The following point score scale was adopted in this study:

1. The date of blooming:

- early blooming species (IV) - 3,

- medium blooming species (turn of IV/V) - 2,

- late blooming species (V) - 1 .

2. Length of flowering:

- short flowering (up to 2 weeks) - 1 ,

- medium flowering (2-3 weeks) - 2,

- long flowering (over 3 weeks) - 3 .

3. Number of inflorescence shoots:

- up to 15 shoots in tuft - 1 ,

- 16-30 shoots - 2,

- over 30 shoots -3 .

4. Sequence of emergence of flowering shoots in tuft:

- almost simultaneously - 1 ,

- continuous - 2 .

5. The phase of coexistence of flowering and fruiting shoots:

- not observed or observed for a short period (up to 5 days) - 1 ,

- markedly evident (over 5 days).

6. Mean inflorescence length:

- up to $2 \mathrm{~cm}-1$,

- over $2 \mathrm{~cm}-2$.

7. The date of emergence of first mature perigynia:

- IV - 3,

- IV/V - 2,

- V/VI - 1 .

8. Mean period of persistence of mature perigynia on the culm:

- short (up to 2 weeks) - 1 ,

- medium (2-4 weeks) - 2,

- long (over 4 weeks) - 3 . 
9. The date of loss of the first perigynia from the shoot:

- IV/V - 1,

- VI/VII - 2,

- VIII - 3 .

Some sedge species bloom again in July or August producing single inflorescence shoots. In the analysed group it sometimes occurs in C. spicata, which markedly enhances its decorative value. However, in the years of the study such a phenomenon was not observed on the analysed tufts.

Since only selected phenological aspects were investigated in this study it was decided not to present phenological spectra for individual stages. Weather factors were not included in the assessment of the results.

No significant differences were recorded in the course of two-year observations in dates of emergence and duration of individual stages and traits. Small differences observed in both years of the study fell within the same ranges.

\section{RESULTS}

In terms of the investigated and assessed inflorescence characteristics the greatest decorative value was found for C. spicata, C. remota and C. pallescens, which received the overall score of 19 points, and C. paniculata - 18 points. In contrast, the lowest values were recorded for $C$. ericetorum (12), C. digitata (13) and C. curta (14). The other species received intermediate values (Table 1 ).

It is difficult to state definitely which of the investigated traits has the most significant decorative value, since it depends on the purpose to be achieved when designing the composition. For this reason when describing the traits it was decided not to grade their decorative value. However, it still needs to be observed that the overall visual effect observed for representatives of individual species remains to be the most important element.

Obviously, the date of emergence of the first flowers, i.e. blooming, is most significant in gardens designed to be attractive already in early spring. Among the described sedges $C$. digitata is the earliest blooming species. However, in terms of decorative value its score is greatly decreased by other parameters, primarily its short blooming time (up to two weeks), the low number of inflorescence shoots in the tuft (frequently much fewer than 15), no sequence or extended emergence of inflorescence shoots and a short period over which mature perigynia are attached on the culm. Carex digitata is a myrmecochoric species and it may be assumed that rapid seed drop may be advantageous for plants, as nutrients contained in elaiosomes are retained over the longest possible period during the vegetation season to attract ants, thus considerably extending the potential seed distribution time by these insects. However, an undisputable advantage of $C$. digitata is the previously mentioned early flowering time and a very decorative perigynium shape, exposed by the morphology of inflorescences. The other species bloom much later.

In terms of the duration of the flowering period, both for female and male flowers, two species are markedly distinguished, i.e. C. spicata and C. panicula$t a$, which may be at anthesis for approx. up to three weeks, which is also connected with a large number of inflorescence shoots in both species. The shortest flowering was observed in C. digitata, while it was a little longer, but still classified to the same grade, in C. curta and C. caespitosa. At the same time C. digitata had the shortest time of maintenance of mature perigynia on the shoot.

The number of inflorescence shoots is this trait which is of great importance for the decorative value of the tuft. Within the analysed group four species had tufts abundant in inflorescence shoots C. spicata, C. paniculata, C. caespitosa and C. vesicaria. At the same time, C. paniculata and C. vesicaria produce vast tufts with arching culms, enhancing their decorative value. The two other species are plants smaller in size, while the obvious advantage of $C$. caespitosa is connected with its inflorescences at approximately the same height on erect, stiff culms. The lowest numbers of shoots in the tuft are found in C. digitata, C. ovalis and C. curta.

A highly appreciated element of flower arrangements, irrespective of the number of species used, is connected with continuous flowering in tufts maintained thanks to the markedly evident sequence of emergence of flowering shoots. This condition is met by three investigated species - C. spicata, C. remota and C. pallescens. This trait is connected with the phase of coexistence of flowering and fruiting shoots, also observed in the three species.

Generally the length of inflorescences has no significant effect on the decorative value of a given specimen. However, it is essential for the desired character of the composition. An additional decorative element in some species is provided by the markedly varied length of inflorescences within individual plants, particularly in combination with the varied shoot height. Within the investigated group the longest inflorescences were found in C. pseudocyperus.

The date of emergence of the first mature perigynia is a major criterion in the selection of species for ornamental purposes. This is first of all due to the fact that between individual species we observe a marked morphological variation in perigynia both in terms of their size, shape, colour and arrangement on the inflorescence axis. This has a considerable effect on the appearance of inflorescences themselves, e.g. ranging from loose to more or less compact. As a rule all the investigated species have an interesting habit of perigynia, since this group was selected so 


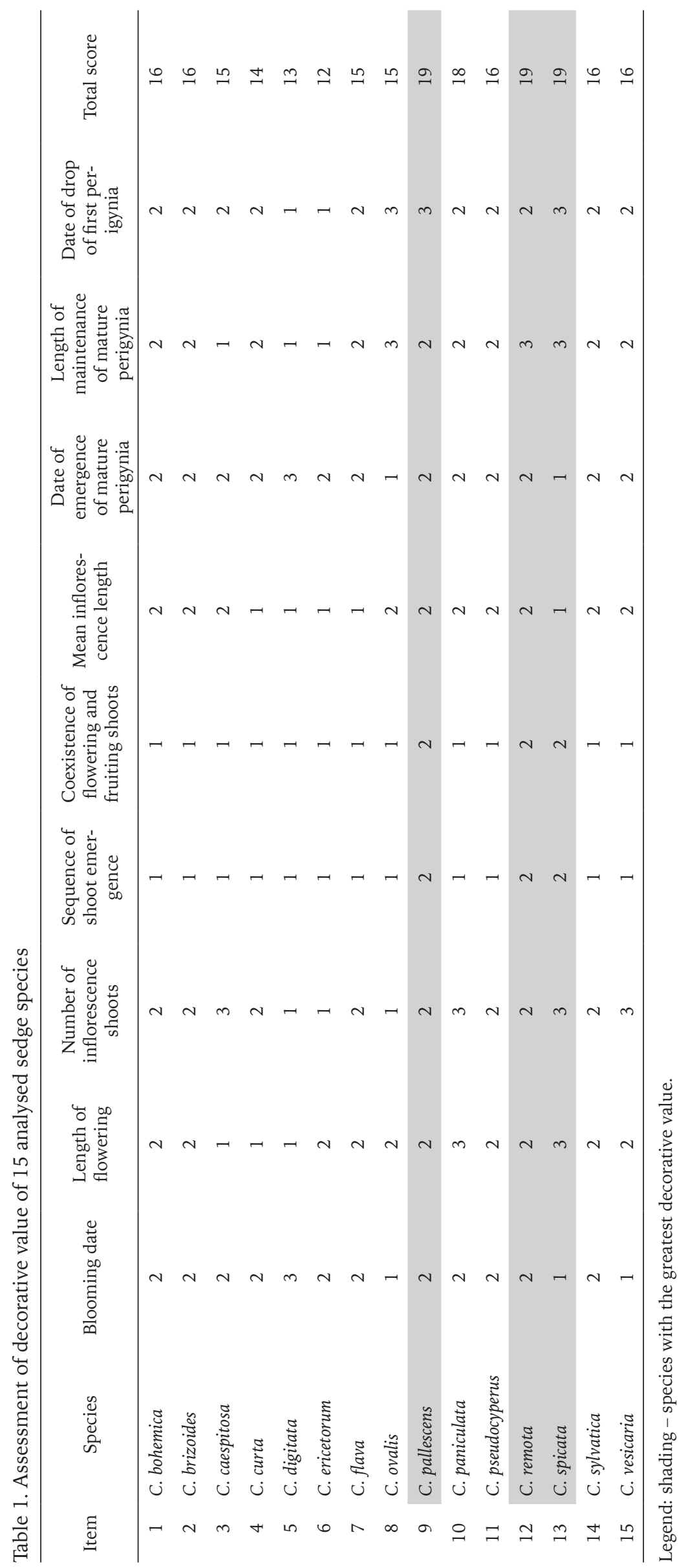


that the full spectrum of perigynium shapes found in the genus Carex may be fully used. In this respect we need to mention C. digitata, C. pseudocyperus, C. fla$v a$, C. pallescens and C. bohemica. The latter species is of particular interest, among other things due to the presence of a very long beak at the perigynium apex, as well as specific inflorescences, morphologically different from those in other sedge species.

The mean duration of maintenance of mature perigynia on the culm is a significant factor in the selection of species for the value of their inflorescences. Mature perigynia remain the longest, i.e. over four weeks, on shoots in C. spicata, C. remota and C. ovalis. In contrast, this period is the shortest (max. 2 weeks) in C. digitata, C. ericetorum and C. caespitosa. Such a short period markedly reduces suitability of representatives of a given species as ornamental plants. This is particularly disadvantageous in species with other particularly attractive traits, e.g. the shape of perigynia in $C$. digitata, or an interesting, cylindrical share of inflorescences composed of round and flattened, overlapping and densely arranged perigynia in C. caespitosa. A related trait is connected with the date of drop of the first perigynia from shoots. In this case it was observed the earliest in C. digitata and C. ericetorum, while it was the latest in C. spicata, C. ovalis and C. pallescens.

A synthetic approach to the comprehensive assessment of the investigated traits in individual species may constitute the foundation for the qualification of a given taxon as ornamental plants. However, frequently in garden landscape design an important role is played by single individual traits, desirable in a specific composition.

\section{CONCLUSIONS}

Sedges may be used as ornamental plants thanks to several traits, primarily the unique structure of their inflorescences, morphology of their perigynia and an interesting habit, but also the varied dates of individual phenological stages, particularly their extended duration between species. Phenology of sedges has not been thoroughly investigated. This results mainly from problems with observation of dates and onset of individual stages, which are caused by the complicated structure of generative parts of sedges. A particularly large number of bract-covered male and female flowers makes it difficult or even impossible to distinguish the flowering phase of female flowers from the early fruit ripening phase. This results from the enclosure of the fruit (nut) inside the perigynium, which is visible already during flowering. This prevents observations of the ovary, thus often the only sign of fertilisation is the drying of stigmas. Unfortunately, it is not always a reliable fertilisation indicator due to the tendency of pistil stigmas to dry out at water deficit.
An additional element hindering observations in some species, e.g. C. paniculata, is connected with the simultaneous occurrence of several dozen up to over 100 inflorescence shoots within one tuft.

For this reason when sedges are used as elements of garden design compositions it is important to focus not on the specific dates of successive development stages in plants, but rather on their overlapping between individual species. This makes it possible to achieve the effect of alternating flowering and fruiting phases in individual species. Additionally, already during the flowering phase we may take advantage of the strong variation both in the morphology of inflorescences and perigynia themselves. This promotes the use of the discussed plants both in planting arrangements of different species, to supplement the composition, but first of all in plantings comprising only representatives of the Carex genus taking advantage also of other traits, not investigated in this study, e.g. traits of vegetative organs, tuft habit, varied tuft size and plant height or leaf colour.

In conclusion it needs to be stressed that sedges planted in gardens are highly desirable elements of the landscape, particularly thanks to the effect of plasticity, observed as a rule in each species throughout the vegetation season.

\section{REFERENCES}

Fech J.C., Lindgren D.T., Streich A.M., Todd K.A. (2007): Ornamental grasses for Nebraska Landscapes. Nebraska Guide. University of Nebraska, Nebraska.

Foerster K. (1982): Einzug der Graser Farne in die Garten. Neuman Verlag, Leipzig.

GrabowsKa B., Kubala T. (2011): Encyklopedia bylin. Zysk i S-ka, Poznań.

Hoffmann A.A., Camac J.S., Williams R.J., Papst W., Jarrad F.C., Wahren C.H. (2010): Phenological changes in six Australian subalpine plants in response to experimental warming and year-to-year variation. Journal of Ecology 98 (4): 927-937.

PudelsKa K. (2007): Wykorzystanie kilkupędowych sadzonek w rozmnażaniu ozdobnych gatunków traw z rodzaju Festuca, Carex i Juncus. Roczniki Akademii Rolniczej w Poznaniu 383, Ogrodnictwo 41: 171-175.

RAK J. (2009): Trawy ozdobne. Multico, Warszawa.

RatlifF R.D., WestFal S.E. (1992): Nebraska sedge (Carex nebraskensis Dewey): Phenology and life history at Tule Meadow, Sierra National Forest, California. Journal of Range Management 45 (2): 210-215.

Stenström A., Wagner I.S. (2008): Effects of simulated climate change on phenology and life history traits in Carex bigelowii. Nordic Journal of Botany 24 (3): 355-371. 
URBAŃSKi P. (2001): Trawy ozdobne, turzyce i sity. PWRiL, Warszawa.

Wagner J., Reichegger B. (1997): Phenology and seed development of the alpine sedges Carex curvula and Carex firma in response to contrasting topoclimates. Arctic and Alpine Research Journal 29 (3): 291-299. 